\title{
Immune Deficiency in CHARGE Association
}

\author{
Demetrios S. Theodoropoulos, MD, Department of Allergy, Marshfield Clinic, Marshfield, Wisconsin, \\ Departments of Internal Medicine and Pediatrics, University of Wisconsin Medical School, Madison, Wisconsin
}

\begin{abstract}

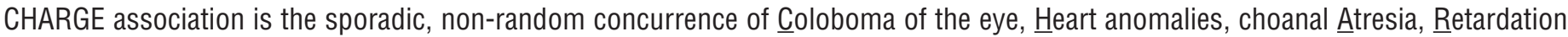
of growth and development, Genitourinary anomalies, Ear anomalies and deafness (CHARGE association). Other abnormalities have also been reported in small numbers of patients with CHARGE association. The molecular basis of the CHARGE association is not clear. The spectrum of CHARGE association anomalies is wide and includes multiple systems. CHARGE association shares features with DiGeorge sequence, but no specific immune abnormalities are identified with the CHARGE association. The present study reports immune defects observed in three patients with CHARGE association. All patients presented with frequent upper and lower respiratory infections. The underlying immune abnormalities differ: one patient has impaired T-cell proliferation and poor antibody response to polysaccharide (pneumococcal) antigens; another has T-cell lymphopenia; and the third has a mild IgG $\mathrm{g}_{2}$ subclass deficiency. Their course has so far been benign and they are all managed with prophylactic antibiotics. Although no single abnormality of the immune system is recognized in these patients, immune deficiency is considered among the occasional components of the CHARGE association.
\end{abstract}

\section{INTRODUCTION}

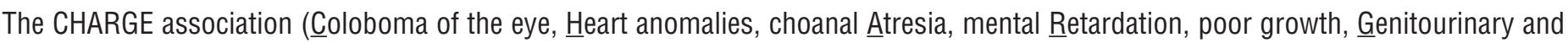
Ear anomalies) includes a group of non-randomly associated anomalies in patients with normal chromosomes. The CHARGE association components and their frequency are listed in table 1.1-3 Other CHARGE association findings include tracheoesophageal fistula, gastroesophageal reflux, dysphagia, facial palsy, micrognathia, cleft lip/palate, central nervous system malformations, ocular hyper-

telorism, microcephaly, omphalocele, rib anomalies and cranial nerve anomalies such as optic nerve malformations and ptosis. ${ }^{4-6}$ The CHARGE association is defined as an "axial mesodermal dysplasia." This wide spectrum of disorders includes entities with similarities in their phenotypes, such as DiGeorge sequence, 22q11 deletion syndrome, Fanconi anemia, VATER association, Holt-Oram syndrome, thrombocytopenia-aplastic radius syndrome, trisomy 13 , etc. ${ }^{7}$ The overlap among the features of these disorders is large enough to present major diagnostic challenges, and often long-term follow-up is necessary to establish a diagnosis in patients with atypical presentation. 8,9

RECEIVED: March 11, 2002

REVISED AND ACCEPTED: May 15, 2002

REPRINT REQUESTS:

Demetrios Theodoropoulos, MD

Department of Allergy

Marshfield Clinic

1000 North Oak Avenue

Marshfield, WI 54449

Telephone: 715-387-5186

Fax: 715-389-3808

Email: theodoropoulos.demetrios@marshfieldclinic.org
KEYWORDS:

Immune deficiency; CHARGE association; T-cell deficiency; Humoral deficiency; Antibody deficiency 


\section{CASE 1 ( $\lg _{2}$ SUBCLASS DEFICIENCY)}

Patient 1 presented at 30 months of age. Her diagnosis of CHARGE association was made by a clinical geneticist based on retinal colobomas, choanal atresia, malformed ears with cochlear abnormalities, patent ductus arteriosus (PDA), severe gastroesophageal reflux, poor height gain in spite of normal length at birth and mild mental retardation. Karyotype and fluorescent in situ hybridization for 22q deletion were normal. Patient 1 presented with a history of recurrent respiratory infections. She had nine episodes of bronchiolitis and/or pneumonia in the past 12 months. She also had a large number of ear infections and required two sets of pressure equalization tubes. Rhinoscopy revealed narrowing of nasal passages. The patient also had a history of urticaria and eczema, and positive skin tests for dairy products and soy. Her past medical history included severe gastrointestinal reflux, Nissen fundoplication, and PDA ligation at birth.

On physical exam, the patient's vital signs were normal. Height at 32 months of age was $83 \mathrm{~cm}$, which is below the 5 th percentile (height age $=20$ months). Height increased over the following 6 months parallel to the 5 th percentile. Weight was $12 \mathrm{~kg}$, which was between the 10th-25th percentile for age. Ear exam revealed absent anthelices and canals rotated downward. Pressure equalizing tubes were present on both sides. Oropharyngeal exam showed high palate. Tonsils were present. Neck exam was normal. Chest inspection was significant for PDA repair scar. Heart exam showed a regular rate and rhythm with no murmurs. The abdomen was soft. The liver and spleen were not enlarged. A scar from Nissen fundoplication was present. Extremities were normal with full range of motion. There were no rashes. Neurologic exam was significant for hypertonia. Skin testing was positive for casein and milk.

The immune function test results are shown in table 2 . Hemogram was normal. IgG and $\operatorname{IgG}_{1}, \operatorname{IgG}_{3}$, and $\mathrm{IgG}_{4}$ subclasses were within the normal range. $\operatorname{IgG}_{2}$ level was below the normal range. Diphtheria and tetanus antibodies were within the protective range. Post-vaccination pneumococcal antibody titers 10 weeks following vaccination showed protective titers for 6 of 12 serotypes. The patient was diagnosed with $\mathrm{IgG}_{2}$ subclass deficiency and was placed on prophylactic trimethoprim-sulfamethoxazole. Since then, she has not suffered any upper or lower respiratory tract infections.

\section{CASE 2 (ANTIBODY DEFICIENCY AND IMPAIRED T-CELL PROLIFERATION)}

Patient 2 was assessed at the age of 3 . He had multiple congenital anomalies consistent with CHARGE association. These included truncus arteriosus, choanal atresia, feeding problems that had been managed with a gastrostomy, retinal

Table 1. Features of CHARGE association. ${ }^{\ddagger}$

Colobomatous malformations

Heart defects

Atresia choanae

Growth deficiency

Developmental delay

Genital hypoplasia

Ear anomalies/deafness

Cranial nerve dysfunction

Renal anomalies

Abdominal defects

Occasional finding
Range from isolated iris coloboma without visual impairment to clinical anophthalmos.

Retinal colobomas are the most common malformations.

Tetralogy of Fallot, patent ductus arteriosus (PDA), ventricular septal defect, atrial septal defect, right-sided aortic arch.

Membranous and/or bony.

Usually postnatal.

Ranges from mild to profound.

Incomplete pubertal development. In males: micropenis, cryptorchidism. In females: hypoplastic labia.

Range from small ears without malformation of the pinna to cupshaped ears. Deafness may be either sensorineural (VIII) or mixed sensorineural and conductive, ranging from mild to profound.

Anosmia (I), facial palsy, ptosis (VII), swallowing problems (IX, X).

Renal dysgenesis, ectopic/horseshoe kidney, hydronephrosis.

Inguinal hernia, omphalocele (rare).

Micrognathia, cleft lip/palate, ocular hypertelorism, microcephaly DiGeorge sequence, tracheoesophageal fistula, anal atresia/stenosis, rib anomalies, hand anomalies, scoliosis, hemivertebrae.

\footnotetext{
¥Adapted from Smith’s Recognizable Patterns of Human Malformation. Frequency of findings in parentheses. ${ }^{1,2}$
} 


\begin{tabular}{|c|c|c|c|c|c|c|c|}
\hline & \multicolumn{2}{|c|}{ Patient 1} & \multicolumn{2}{|c|}{ Patient 2} & \multicolumn{2}{|c|}{ Patient 3} & \multirow[b]{2}{*}{ Reference } \\
\hline & Initial & $\begin{array}{l}\text { After } \\
9 \mathrm{mo}\end{array}$ & Initial & $\begin{array}{l}\text { After } \\
12 \text { mo }\end{array}$ & Initial & $\begin{array}{l}\text { After } \\
4 \mathrm{mo}\end{array}$ & \\
\hline \multicolumn{8}{|l|}{ Immunoglobulins } \\
\hline $\lg G$ & 485 & 579 & 507 & & 609 & & $335-975 \mathrm{mg} / \mathrm{dl}$ \\
\hline $\lg A$ & 25 & 40 & 91 & & 40 & & $17-70 \mathrm{mg} / \mathrm{dl}$ \\
\hline $\lg M$ & 102 & 138 & 60 & & 51 & & $22-124 \mathrm{mg}-31$ \\
\hline $\lg \mathrm{E}$ & 11 & & 8 & & 37 & & $0-17 \mathrm{IU} / \mathrm{ml}$ \\
\hline \multicolumn{8}{|l|}{ IgG subclasses } \\
\hline $\lg G_{1}$ & 358 & & 289 & & 453 & & $313-961 \mathrm{mg} / \mathrm{dl}$ \\
\hline $\lg G_{2}$ & 56 & & 125 & & 88 & & $65-456 \mathrm{mg} / \mathrm{dl}$ \\
\hline $\lg G_{3}$ & 46 & & 66 & & 38 & & $11-125 \mathrm{mg} / \mathrm{dl}$ \\
\hline $\operatorname{lgG}_{4}$ & 25 & & 27 & & 31 & & $1-70 \mathrm{mg} / \mathrm{dl}$ \\
\hline \multicolumn{8}{|l|}{ Responses to vaccination } \\
\hline Diphtheria antibodies & $>5.00$ & & 0.06 & & & & $>0.10 \mathrm{IU} / \mathrm{ml}$ \\
\hline Tetanus antibodies & 1.74 & & 0.10 & & & & $>0.10 \mathrm{IU} / \mathrm{ml}$ \\
\hline Haemophilus influenzae B & & & & & $>22.0$ & & $>2.0 \mu \mathrm{g} / \mathrm{ml}$ \\
\hline Influenza A antibodies & $>1: 8$ & $1: 16$ & & & $>1: 8$ & & $<1: 8$ \\
\hline Influenza B antibodies & $>1: 8$ & & & & $>1: 8$ & & $<1: 8$ \\
\hline Pneumococcal antibodies & $5 / 12$ & & $6 / 12$ & $0 / 12$ & $6 / 12$ & & Protective antibodies for 12 serotypes \\
\hline \multicolumn{8}{|l|}{ Cell surface markers } \\
\hline CD3 (\%) & 57 & & 46 & & 21 & 19 & $59-87$ \\
\hline CD3 absolute & 2.993 & & 0.676 & & 0.504 & 0.416 & $1.180-6.960 \times 10^{9} / 1$ \\
\hline $\mathrm{CD}^{+}{ }^{+} \mathrm{CD} 4^{+}(\%)$ & 39 & & 29 & & 19 & 16 & $29-57$ \\
\hline $\mathrm{CD}^{+}{ }^{+} \mathrm{CD} 4^{+}$absolute & 2.047 & & 0.426 & & 0.456 & 0.350 & $0.650-3.650 \times 10^{9} / 1$ \\
\hline $\mathrm{CD}^{+}{ }^{+} \mathrm{CD} 8^{+}(\%)$ & 16 & & 15 & & 2 & 2 & $7-31$ \\
\hline $\mathrm{CD}^{+}{ }^{+} \mathrm{CD} 8^{+}$absolute & 0.840 & & 0.221 & & 0.048 & 0.044 & $0.160-1.980 \times 10^{9} / 1$ \\
\hline $\mathrm{CD} 4 /{ }^{+} \mathrm{CD} 8{ }^{+}$ratio & 2.44 & & 1.93 & & 9.50 & 8 & $1.00-3.50$ \\
\hline CD45 (\%) & 100 & & 100 & & 100 & 100 & \\
\hline $\mathrm{CD}^{-}{ }^{-} \mathrm{CD} 16^{+} \mathrm{CD} 56^{+}(\%)$ & 17 & & 16 & & 26 & 26 & $0-18$ \\
\hline $\mathrm{CD}^{-} \mathrm{CD} 16^{+} \mathrm{CD}^{2} 6^{+} \mathrm{absol}$ & 0.893 & & 0.235 & & 0.624 & 0.569 & $0.000-1.440$ \\
\hline CD19 (\%) & 25 & & 37 & & 53 & 54 & $6-19$ \\
\hline CD19 absolute & 1.313 & & 0.544 & & 1.272 & 1.183 & $0.150-1.520 \times 10^{9} / 1$ \\
\hline \multicolumn{8}{|l|}{ Mitogen stimulation } \\
\hline Mitogen control & 1893 & & 14,058 & & 863 & & $>50$ \\
\hline Phytohemagglutinin & 271,852 & & 95,118 & & 388,752 & & $>188,880$ \\
\hline Pokeweed & 184,725 & & 45,415 & & 109,556 & & $>68,549$ \\
\hline Concanavalin A & 288,284 & & 51,333 & & 248,444 & & $>81,283$ \\
\hline Staph A Cowen strain & 61,553 & & 15,706 & & 29,939 & & $>3,412$ \\
\hline \multicolumn{8}{|l|}{ Antigen stimulation } \\
\hline Candida & & & & & 0.4 & & $>2.0$ (response ratio) \\
\hline Streptomycin & & & & & 0.8 & & $>2.0$ (response ratio) \\
\hline
\end{tabular}

Bold typeface numbers = clinically relevant abnormal values.

Patient 1: Low $\lg _{2}$ levels. Poor response to influenza vaccination. Patient 2: Low IgG levels. Poor response to protein antigens with non-protective diphtheria and tetanus antibody titers after immunization. Loss of protective antibodies against polysaccharide antigens, as evidenced by non-detectable pneumococcal antibodies following immunization. Low $\mathrm{CD}^{+}{ }^{+} \mathrm{T}$-cells. Poor T-cell proliferation demonstrated by impaired response to phytohemagglutinin, concanavalin $\mathrm{A}$ and pokeweed. Patient 3: Poor response to influenza vaccination. Low T-cell counts and low CD4 ${ }^{+}$and $\mathrm{CD} 8^{+}$T-cells. Poor lymphocyte proliferation following antigen stimulation. 
colobomas, malformed ears and growth retardation of postnatal onset. He was hospitalized in infancy for pneumonia and was on ventilation for 10 days. Since then, he suffered frequent infections including otitis media, conjunctivitis and pneumonia. He always had copious nasal secretions and chronic nasal congestion. Patient 2 also had reactive airway disease, treated with albuterol and fluticasone. He had myringotomy with insertion of pressure-equalizing tubes twice.

On physical exam, blood pressure was 96/48, heart rate $100 / \mathrm{min}$, respiratory rate $32 / \mathrm{min}$. Length was $86 \mathrm{~cm}$ (height age $=22$ months) and weight was $12.5 \mathrm{~kg}$, both of which were below the 5 th percentile for age. Over the following 12 months height remained below the 5 th percentile, but kept increasing parallel to it. Weight increased to the 10th percentile for age. Ear exam showed hypoplastic anthelices and tortuous canals. Ear tubes were in place. Nasal mucosa appeared swollen with cloudy white secretions.

Oropharyngeal exam revealed thick secretions in the posterior pharyngeal wall. Cervical lymphadenopathy was present. Lung exam revealed good air exchange bilaterally. Cardiovascular exam revealed a II/VI systolic murmur over the aortic and pulmonary areas. Abdominal exam was normal. Neurologic exam revealed slight hypertonia.

Laboratory data are shown in table 2 . The hemogram was normal. There was a slight decrease in the relative percentage of CD4 positive T-cells with a corresponding slight increase in the percentage of NK cells and B cells, but the absolute numbers of all these cells were normal. $\operatorname{IgA}$, $\operatorname{IgM}$, and $\operatorname{IgE}$ levels were normal. IgG level was within normal limits at 507 $\mathrm{mg} / \mathrm{dl}$. $\mathrm{IgG}_{1}$ was below normal level, but other IgG subclasses were all within normal range. Tetanus antibodies were normal, whereas antibodies against diphtheria, influenza and pneumococcal vaccines were all low. Mitogen proliferation studies were abnormal for phytohemagglutinin, concanavalin A and pokeweed. Cell population studies showed borderline low $\mathrm{CD}^{+}$T-cells. The B-cell population and function were normal as evidenced by normal to high B-cells in cell surface marker studies, normal response to Staphylococcus aureus Cowan strain and immunoglobulin levels. Case 2 was diagnosed with antibody deficiency affecting the $\operatorname{IgG}_{1}$ subclass. The poor T-cell proliferative response to mitogens indicates a T-cell involvement in the pathogenesis of the antibody deficiency. Prophylaxis with amoxicillin/clavulanate alternating with clarithromycin every other month resulted in a lower rate of upper respiratory tract infections.

\section{CASE 3 (T-CELL LYMPHOPENIA AND SUBNORMAL ANTIGEN STIMULATION STUDIES)}

Patient 3 was first assessed at 22 months of age. His neonatal history included hypocalcemia and seizures due to hypoparathyroidism. He had retinal colobomas, choanal atresia, impaired hearing, malformed ears, severe gastroesophageal reflux requiring Nissen fundoplication and G-tube insertion, pulmonic valvular stenosis, patent foramen ovale and PDA. Patient 3 was hospitalized at 2 weeks of age and at 4 weeks of age for respiratory distress due to bronchiolitis. He required intubation on both occasions. Reactive airway disease/asthma, and laryngo/tracheo/bronchomalacia have been diagnosed. The patient history of chronic sinusitis, heart disease multiple episodes of conjunctivitis, and recurrent otitis media with eustachian tube dysfunction requiring pressure-equalizing tubes. A third hospitalization was required to treat dehydration following rotavirus infection.

On physical exam, height was $81.4 \mathrm{~cm}$ (5th percentile, height age $=17$ months). Height has remained at the 5 th percentile. Weight was $10.9 \mathrm{~kg}$ (10th percentile). There was facial asymmetry with left facial hypoplasia. Nasal mucosa was red and swollen with large amounts of clear discharge. Ears were malformed, small, and posteriorly rotated with pressure equalizing tubes in place. Heart exam revealed a grade IIIII/VI harsh systolic ejection murmur maximal at the left upper sternal border, radiating to the axillae and back. Abdomen was soft with a midline scar from Nissen fundoplication and G-tube insertion. Genitourinary exam was normal.

Chromosomal analysis was normal. Fluorescent in situ hybridization for $22 \mathrm{q}$ microdeletions ruled out DiGeorge syndrome, velocardiofacial syndrome and other 22q11 deletions. Immunoglobulins were normal. $\mathrm{CD}^{+}$cells were below normal. Mitogen stimulation tests were normal, but antigen stimulation studies showed a suboptimal response. He was diagnosed with T-cell deficiency. The patient received Synagis for respiratory syncytial virus prophylaxis and was started on trimethoprim-sulfamethoxazole. His treatment included nasal and inhaled steroids for rhinitis and asthma.

\section{DISCUSSION}

Severe combined immune deficiency in a patient with CHARGE association has been reported once. ${ }^{10}$ The patient had hemorrhagic diarrhea at the age of 6 months.

Colonoscopy and biopsy showed ulcerative malacoplakia. $\mathrm{CD}^{+}$lymphopenia, absence of thymus and extreme hypoplasia of the follicular cortex were demonstrated in lymph node biopsy. Over the following months B-cell counts progressively declined. In later stages, plasma cells could not be detected in colon mucosa or lymph nodes. The patient died of respiratory failure at 18 months of age following recurrent respiratory infections. ${ }^{10}$

Humoral immune defects have been reported in patients with CHARGE association. ${ }^{11}$ Chronic rotavirus gastroenteritis has been reported in a patient with features consistent with CHARGE association and DiGeorge sequence. The patient had right-sided choanal atresia, left facial paralysis, malformed left pinna, left-sided congenital glaucoma, micropenis and atrial septal defect. He also had hypoplastic parathyroids and thymus. Enzyme-linked immunosorbent assay failed to show any serum rotavirus-specific antibody response. Despite 
treatment with thymic hormone and weekly intravenous gammaglobulin infusions, the patient failed to thrive and died at age 5 months. ${ }^{11}$ The defective immune response to rotavirus in this patient is in contrast to studies of mouse models, which indicates that host defense against murine rotavirus requires neither functional T-lymphocytes nor specific antibodies. ${ }^{12}$

Among chromosomal abnormalities reported in patients with CHARGE association, there is an inverted duplication in the $14 q 22-24$ region next to the $14 q 32$, the band where heavy chain genes for immunoglobulin isotypes map. ${ }^{13}$ This patient was a 4-year-old girl with recurrent ear and sinus infections who required myringotomy tubes at age 14 months and was treated with intravenous immunoglobulin infusions every 3 weeks for hypogammaglobulinemia with $\mathrm{IgG}_{2}$ subclass deficiency. T-cell function was normal. ${ }^{13}$

Large structural aberrations of chromosomes 2 and 22, where the light chain genes are located, have also been described in CHARGE association. ${ }^{14}$ One of these patients with a translocation involving chromosome $22 \mathrm{q}$ had a mild T-cell dysfunction with decreased T-cell numbers to approximately "half of normal values." CD4/CD8 ratio was normal (1.7). By the age of 2 years 7 months the patient had suffered multiple respiratory infections. ${ }^{14}$

A patient with CHARGE association has also been described with a translocation involving the $6 \mathrm{p}$ area where the human leukocyte antigen loci complement components and the tumor necrosis factor are mapped. ${ }^{15}$ This patient had left choanal atresia, right facial nerve palsy, tracheoesophageal fistula (surgically repaired), large ventricular septal defect, overriding aorta and infundibular pulmonary stenosis, and hypotonia without any focal neurologic signs. Differential diagnosis included VATER association (Vertebrae, Anal, Trachea, Esophagus, Radius problems) as he also had hemivertebrae. He died in the first few weeks of life with septicemia, pneumonia and early meningitis. No immune function studies were reported. ${ }^{15}$

A number of occasional chromosomal aberrations have been reported in patients with CHARGE association. Some of them involve loci relevant to immune maturation and function. Among these aberrations 22q11.2 microdeletions are the most intriguing, as they raise the question of DiGeorge syndrome or velocardiofacial syndrome. ${ }^{16,17}$ In a series of 18 patients with CHARGE association, one patient was diagnosed with deletion $22 \mathrm{q} 11.2{ }^{16}$ There is no information as to the immune function of these patients with CHARGE association and 22q11.2 deletions. Genes responsible for thymus development map in this region, as is evidenced by DiGeorge syndrome and other conditions associated with deletions in $22 \mathrm{q} 11$.
The etiology of CHARGE association is unclear. Most cases are sporadic. Familial cases have, however, been described. ${ }^{18}$ The occurrence of Mendelian inheritance in CHARGE association may justify the use of the term "CHARGE syndrome" (as opposed to "CHARGE association"), at least for familial cases. ${ }^{19}$ Kushnick et al described a patient with CHARGE association, agonadism, and absent ZFY (Y-linked zinc finger protein). ${ }^{20} \mathrm{ZFY}$ has been considered in the past as a candidate gene for the testis-determining factor. In marsupials, sequences homologous to the ZFY map to autosomes. ${ }^{21}$ Although their function has not been fully delineated yet, the encoded protein of ZFY binds to nucleic acids in a sequencespecific manner to regulate transcription. The development of CHARGE association in Kushnick's patient may be the result of dysregulation in the transcription process rather than a $\mathrm{Y}$ chromosome defect. At the present time there is no evidence that ZFY proteins may be involved with immune function.

With the exception of growth deficiency, which is usually postnatal, the major CHARGE association anomalies (choanal atresia, eye colobomas, esophageal atresia and impaired heart septation) can all be dated to a common period of embryologic development that spans days 35 to 45 post-conception. The development of thymus and parathyroid glands from the third and fourth pharyngeal pouches and their caudal migration occur at the same time. Full separation of the parathyroid glands from thymus and assumption of their final position occurs between 44 and 52 days post-conception. Interestingly, the differential diagnosis between CHARGE association and DiGeorge syndrome is sometimes jeopardized by the presence of abnormalities, typical for DiGeorge syndrome in patients with CHARGE association and vice versa. Hypoparathyroidism with hypocalcemic seizures has been described in patients with fully developed CHARGE association, and choanal atresia has been described in a few patients with otherwise typical DiGeorge syndrome. In fact, the term "DiGeorge sequence" allows the recognition of a DiGeorge pattern of anomalies without necessarily excluding the diagnosis of CHARGE association. ${ }^{1}$ The spectrum of anomalies traced to the 35 to 45 day post-conception period are shared by the DiGeorge syndrome and the CHARGE association. ${ }^{1}$ This set of anomalies is expanded by the present report to include defects of the parathyroid, heart, esophagus, midfacial region and other abnormalities. Adaptive immunity defects may be related to defects in thymic development.

With the present report, the number of patients showing evidence of immune deficiency with CHARGE association rises to seven. ${ }^{10,11,13,14}$ Immune defects can only be hypothesized in another case on the basis of fulminant infection otherwise unexplained. ${ }^{15}$ Interestingly, the nature of the recorded defects and their severity vary from mild IgG subclass deficiency manifesting with recurrent respiratory infections to the severe combined immune deficiency reported previously. ${ }^{10} \mathrm{~T}$ cell defects, with or without thymus hypoplasia, were present in two of the patients of the present study (Patients 2 and 3) 
and in three previously reported patients. ${ }^{10,11,14} \mathrm{IgG}_{2}$ subclass deficiency with or without hypogammaglobulinemia has been noted in the present study (Patient 1) and reported previously. ${ }^{13}$ DiGeorge sequence was considered in the differential diagnosis of Patient 3 and was identified in only one of the previously reported patients with documented immune deficiency. ${ }^{11}$

It is possible that the pathophysiology of immune deficiency in CHARGE association may be heterogeneous, just as CHARGE association itself is heterogeneous. Perhaps some cases reported presently or in the previous publications $10,11,13,14$ are isolated familial syndromes with CHARGE association features rather than true CHARGE associations. A single underlying cause of immune deficiency in CHARGE association cannot be dismissed. A defect in DNA-protein interaction can be hypothesized, which may affect genes responsible for the development of adaptive immunity. This follows from the phenotypic overlap of CHARGE association cases with DiGeorge syndrome/sequence cases. 1,11 CHARGE association cases with agonadism are associated with a presumed ZFY absence, ${ }^{20}$ deleted $22 \mathrm{q} 11.2,{ }^{16}$ and/or other relevant chromosomal aberrations. ${ }^{13-15}$ The complex nature of DNA-protein interactions via zinc-finger proteins and the existence of widespread zinc-finger homologous DNA sequences throughout the genome could explain the variety and heterogeneity of the observed immune defects.

\section{CONCLUSION}

Patients with CHARGE association are predisposed to respiratory infections because of extensive sinus, nasal and ear malformations, and frequent presence of gastroesophageal reflux or neurological abnormalities. In addition to these factors, recurrent infections in patients with CHARGE association may be due to immune defects. Thymus-dependent immunity may be affected in CHARGE association. A high index of suspicion is required for patients with CHARGE association presenting with multiple sinopulmonary infections, persistent gastroenteritis, or evidence of invasive infectious disease, such as sepsis, meningitis or osteomyelitis. Immune function evaluation with emphasis on T-cell numbers and proliferative responses, as well as antibody concentrations and specific antibody responses is indicated for those patients with CHARGE association whose infections cannot be accounted for by upper respiratory tract malformations.

All three patients reported are currently managed with prophylactic antibiotics. Frequent follow up with imaging studies and referrals to qualified specialists are needed. It is unclear whether the described abnormalities are of a transient nature, will always respond to prophylactic antibiotics, or will eventually progress to more severe defects.

\section{ACKNOWLEDGMENTS}

The author wishes to thank Marshfield Medical Research Foundation for its support. Mrs. Alice Stargardt's diligence and attention to detail in the preparation of this manuscript are greatly appreciated.

\section{REFERENCES}

1. Jones KL. Smith's Recognizable Patterns of Human Malformation, 5th edition. WB Saunders Company: Philadelphia. 1997; pp 616-617, 668-670.

2. Blake KD, Davenport SL, Hall BD, Hefner MA, Pagon RA, Williams MS, Lin AE, Graham JM Jr. CHARGE association: an update and review for the primary pediatrician. Clin Pediatr 1998; 37:159-174.

3. Edwards BM, Van Riper LA, Kileny PR. Clinical manifestations of CHARGE association. Int J Pediatr Otorhinolaryngol 1995; 33:23-42.

4. Byerly KA, Pauli RM. Cranial nerve abnormalities in CHARGE association. Am J Med Genet 1993; 45:751-757.

5. Hall BD. Choanal atresia and associated multiple anomalies. J Pediatr 1979; 95:395-398.

6. Pagon RA, Graham JM Jr, Zonana J, Yong SL. Coloboma, congenital heart disease, and choanal atresia with multiple anomalies: CHARGE association. J Pediatr 1981; 99:223-227.

7. Russell LJ, Weaver DD, Bull MJ. The axial mesodermal spectrum. Pediatrics 1981; 67:176-182.

8. Theodoropoulos DS. VATER association: a guide to diagnosis by exclusion. Bull Hematol 2000; 28(1;2/3):5-10.

9. Wilson DI, Burn J, Scambler P, Goodship J. DiGeorge syndrome: part of CATCH 22. J Med Genet 1993; 30:852-856.

10. Boudny P, Kurrer MO, Stamm B, Laeng RH. Malakoplakia of the colon in an infant with severe combined immunodeficiency (SCID) and charge association. Pathol Res Pract 2000; 196:577-582.

11. Wood DJ, David TJ, Chrystie IL, Totterdell B. Chronic enteric virus infection in two T-cell immunodeficient children. J Med Virol 1988; 24:435-444.

12. Eiden J, Lederman HM, Vonderfecht S, Yolken R. T-cell-deficient mice display normal recovery from experimental rotavirus infection. J Virol 1986; 57:706-708.

13. North KN, Wu BL, Cao BN, Whiteman DA, Korf BR. CHARGE association in a child with de novo inverted duplication $(14)(\mathrm{q} 22 \rightarrow \mathrm{q} 24.3)$. Am J Med Genet 1995; 57:610-614.

14. Clementi M, Tenconi R, Turolla L, Silvan C, Bortotto L, Artifoni L. Apparent CHARGE association and chromosome anomaly: chance or contiguous gene syndrome. Am J Med Genet 1991; 41:246-250.

15. Hurst JA, Meinecke P, Baraitser M. Balanced $t(6 ; 8)(6 p 8 p ; 6 q 8 q)$ and the CHARGE association. J Med Genet 1991; 28:54-55.

16. Devriendt K, Swillen A, Fryns JP. Deletion in chromosome region 22q11 in a child with CHARGE association. Clin Genet 1998; 53:408-410.

17. Emanuel BS, Budarf ML, Sellinger B, Goldmuntz E, Driscoll DA. Detection of microdeletions of 22q11.2 with fluorescence in situ hybridization (FISH): diagnosis of DiGeorge syndrome (DGS), velocardio-facial (VCF) syndrome, CHARGE association and conotruncal cardiac malformations. Am J Hum Genet 1992; 51(suppl): A3.

18. Davenport SLH, Hefner MA, Mitchell JA. The spectrum of clinical features in CHARGE syndrome. Clin Genet 1986; 29:298-310.

19. Abruzzo MA, Erickson RP. Re-evaluation of new X-linked syndrome for evidence of CHARGE syndrome or association. Am J Med Genet 1989; 34:397-400.

20. Kushnick T, Wiley JE, Palmer SM. Agonadism in a 46,XY patient with CHARGE association. Am J Med Genet 1992; 42:96-99.

21. Sinclair AH, Foster JW, Spencer JA, Page DC, Palmer M, Goodfellow PN, Graves JA. Sequences homologous to ZFY, a candidate human sex-determining gene, are autosomal in marsupials. Nature 1988; $336: 780-783$. 